\title{
Uterine malformations and pregnancy: about 11 cases seen university hospital center of gynecology- obstetric Befelatanana Antananarivo Madagascar
}

\author{
Ibrahim Housni ${ }^{1}$, Ratsiatosika A. Tanjona ${ }^{2}$, Martial A. Rakotonirina ${ }^{1 *}$, \\ Randriamahavonjy Romuald $^{3}$, Sidy Fleurian ${ }^{1}$, Bacar A. Halissoit ${ }^{1}$ \\ Hery A. Rakotovao ${ }^{4}$
}

${ }^{1}$ Departement of Gynecology-Obstetrics, Befelatanana University Hospital Centre, Antananarivo, Madagascar

Received: 31 July 2020

Revised: 23 September 2020

Accepted: 29 September 2020

*Correspondence:

Dr. Martial A. Rakotonirina,

E-mail: andriamarorakotonirina@gmail.com

Copyright: (c) the author(s), publisher and licensee Medip Academy. This is an open-access article distributed under the terms of the Creative Commons Attribution Non-Commercial License, which permits unrestricted non-commercial use, distribution, and reproduction in any medium, provided the original work is properly cited.

\begin{abstract}
Birth defects in the uterus result from abnormal fusion of the miler ducts and / or failure. Uterine malformations are a common cause of infertility, but if pregnancy occurs absorption from the septum. They are relatively frequent and concern $0.1-3 \%$ of the female population, such a situation is potentially high risk obstetric. We report here, 11 cases of uterine malformations during pregnancy seen at the CHUGOB from May 01, 2017 to May 01, 2018. We observed 11 cases of uterine malformations during pregnancy, including 3 cases of didelphus uterus, 3 cases of pseudounicornuate uterus, 3 cases of bicornuate uterus, 1 case of septate uterus and 1 case of true unicornuate uterus. The age of the parturients ranged from 22 to 26 with a mean of 23.63 years. Regarding pregnancy, 5 women were primigest, 4 were paucigest and 2 were multiparous. For gestational age, 09 cases came to term and 2 cases pregnancy stopped at 17 weeks. The average birth weight was $2215 \mathrm{~g}$. The diagnosis of the malformation was made before the caesarean section in 2 out of 10 cases. Eight out of 10 cases of the fetuses were alive. Congenital uterine malformations are often asymptomatic. The occurrence of pregnancy in a malformed uterus is a rare but potentially serious situation. The diagnosis of these abnormalities is based on new advanced imaging means such as 3D ultrasound.
\end{abstract}

Keywords: 3D ultrasound, Pregnancy, Malformation, Uterus

\section{INTRODUCTION}

Congenital uterine malformations result from an abnormal fusion of the Mulerian ducts and/or failure of absorption of the septum. ${ }^{1,2}$ They are relatively common since they affect $0.1-3 \%$ of the female population. ${ }^{3,4,5}$ Many of them are asymptomatic. ${ }^{6,7,8}$ The majority of these are bicornuate uteri $(50 \%)$ and partitioned uteri $(34 \%)$. Unicorn uteri represent only $5 \%$ of cases and are associated with a rudimentary horn (pseudo-unicorn uterus) in $83 \%$ of cases. ${ }^{5}$
Pregnancy in a malformed uterus is rare. However, such a situation is potentially at high obstetric risk. ${ }^{2}$ Pregnancies occurring in a rudimentary horn are serious. They can lead to maternal death due to the uterine rupture which is common. ${ }^{9}$

We report here, eleven cases of uterine malformations on pregnancy seen at the University Hospital of Gynecology-Obstetrics Befelatanana, including three cases of didelphic uterus, three cases of pseudo- 
unicornuate uterus, three cases of bicornuate uterus, one case of septate uterus and one true unicornuate uterus.

\section{CASE SERIES}

\section{Case-1}

This is a 22-year-old primigest woman. In her history, we note hospitalization for a threat of premature delivery in a didelphic uterus (Figure 1) at 34 weeks of amenorrhea. Obstetric ultrasound and hysterosalpingography done in a private center at this age of pregnancy to confirm the existence of a didelphic uterus. She was admitted to the emergency room for water loss ranging from six hours to 37 weeks and 2 days. She was afebrile and the other parameters were normal.

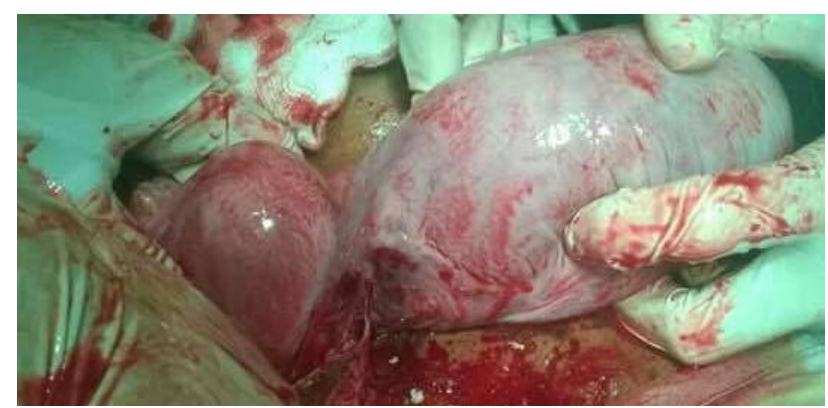

Figure 1: Didelphic uterus after fetal extraction.

The obstetrical examination found 4 contractions in ten minutes. The uterine height was $28 \mathrm{~cm}$. Active fetal movements were positive and fetal heart sounds were 142 beats minutes. Speculum examination confirmed the loss of clear water, and the presence of two cervicals with a vaginal septum. Vaginal examination revealed a closed left neck, a soft right neck dilated to $2 \mathrm{~cm}$ and the pelvis was clinically normal.

A cesarean section is indicated in urgency, allowing to extract a baby in cephalic presentation, male sex, Apgar index of $10 / 10$ and weighing $1680 \mathrm{~g}$. We found a bidelphic uterus with communication at the level of the upper third. The operative consequences were simple. Check-ups for associated malformations were normal.

\section{Case-2}

This is a 29-year-old woman, third gesture with a living child. In his antecedents we note two deliveries by vaginal route. The first childbirth is marked by a born death. She was transferred to the emergency department for cord and hand prolapse at 41 weeks and 3 days after a failed vaginal birth attempt.

Clinical examination showed maternal tachycardia at 119 beats per minute, hypothermia at $35.6^{\circ} \mathrm{C}$ and other unremarkable parameters. The upper uterine is measured at $26 \mathrm{~cm}$. On inspection we observe a procidence of a hand with a transverse presentation. On vaginal examination, the cervix is dilated to $9 \mathrm{~cm}$ with a nonpulsatile cord procidence.

Cesarean section is indicated as an emergency to extract a female baby with hydrocephalus, who died in utero in a remnant of meconium amniotic fluid, weighing $2500 \mathrm{~g}$. On exteriorization of the uterus for hysterography, we found a bicornuate uterus (Figure 2). Checkups looking for associated urinary tract malformations are not done because the patient did not have the necessary financial means.

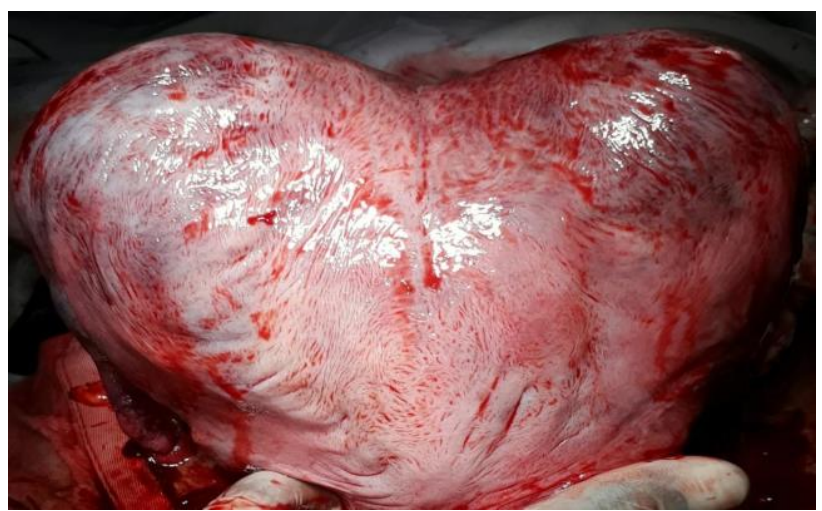

Figure 2: Didelphic uterus after fetal extraction.

\section{Case-3}

This is a 24-year-old woman, second gesture, a living child delivered vaginally. She does not present any particular antecedent. She was admitted to the emergency room for acute abdominal pain at 17 weeks and 2 days, progressing for two days without genital bleeding. The text of urinary pregnancy performed in emergency was positive. Abdominal palpation revealed a fixed hard abdominal mass $5 \mathrm{~cm}$ long in axis and pelvic examination was normal. Emergency abdomino-pelvic ultrasound revealed an ectopic pregnancy with abdominal location. However, an exploratory laparotomy indicated in urgency allowed a resection of a rudimentary horn containing a macerated fetus dead in utero and weighing $200 \mathrm{~g}$ (Figure 3).

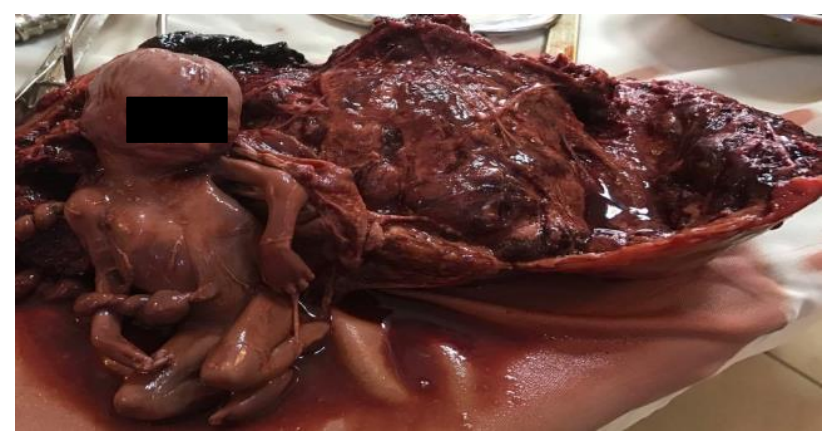

Figure 3: The rudimentary horn and the dead fetus in uterus macerated after incision of the rudimentary horn. 
The operative consequences were simple. In total, it was a pseudo-horn uterus with a rudimentary gravidic horn, the pregnancy of which was localized at the level of the rudimentary horn. Assessments for associated malformations were not carried out due to lack of financial resources.

\section{Case-4}

This is a 22-year-old woman, second procedure, a live child delivered by cesarean section for didelphic uterus (Figure 4). She has no other particular history. She is scheduled at 38 weeks for cesarean section on transverse presentation associated with a didelphic uterus and a united cicatricial uterus. The fundal height was $28 \mathrm{~cm}$ and the remainder of the obstetrical examination was unremarkable. Cesarean section extracted a male baby, Apgar 10/10, weighing 1850 g. On exteriorization of the uterus for hysterotomy, we found that the pregnancy was located in the non-scarring horn. The operative consequences were simple. The results of the associated malformations were normal.

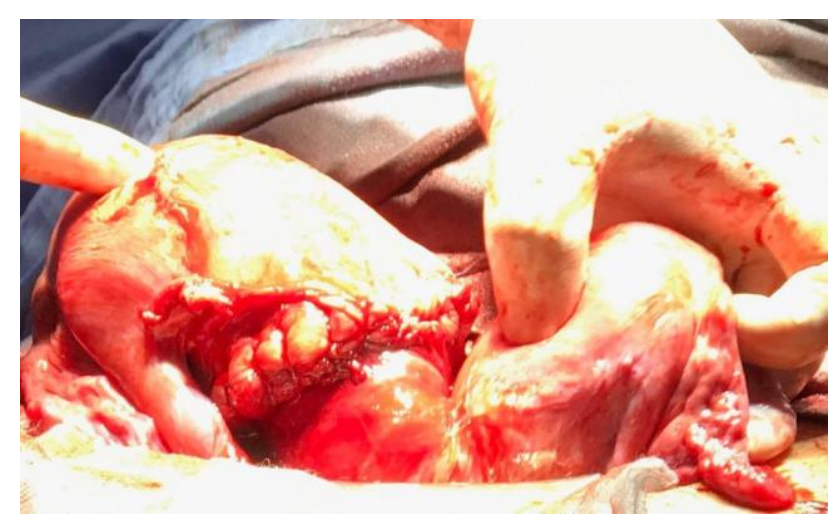

Figure 4: Didelphic uterus with the scar against the side.

\section{Case-5}

This is a 35-year-old woman, fourth gesture, two live children delivered vaginally. In her history, we noted a late spontaneous miscarriage at 17 weeks of amenorrhea and an appendectomy in 2002. She was referred to our center by a level I maternity unit for failure of induction at 42 weeks of amenorrhea and 2 days. The obstetric examination at the entrance revealed a uterine height of $36 \mathrm{~cm}$, a cedematous, posterior, soft cervix dilated to 2 $\mathrm{cm}$ and the rest of the examination unremarkable. The fetal heart rate recording revealed severe fetal tachycardia at 194 beats per minute. An emergency Caesarean section is indicated to extract a baby of a male born asphyxiated, Apgar at 5 in the first minute, 7 in the fifth minute and 8 in the tenth minute and weighing $3500 \mathrm{~g}$. And during this cesarean section we noticed the presence of a rudimentary communicating horn on a pseudo-horn uterus (Figure 5). The operative consequences were simple. The results of the associated malformations were normal.

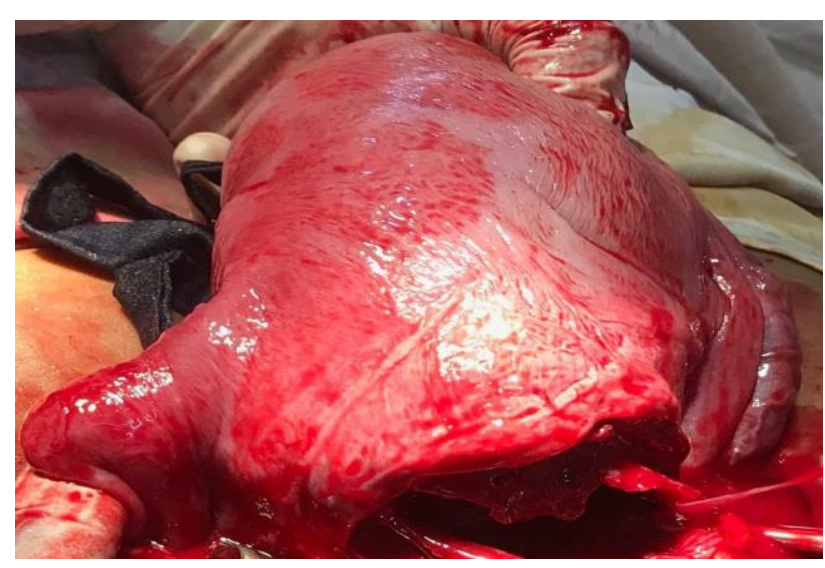

Figure 5: Pseudo-horn uterus with a rudimentary communicating horn after fetal extraction.

\section{Case-6}

It is a 26-year-old woman, primigest with no particular history. She was admitted to the emergency room for ten hours of water loss at 37 weeks of amenorrhea and 3 days. Obstetric examination at entry showed uterine height of $30 \mathrm{~cm}$, speculum examination confirmed meconium loss; and vaginal examination objectified soft cervix, centered dilated to $4 \mathrm{~cm}$ and a fetus in breech presentation. We objectified a fever of $39.5^{\circ} \mathrm{C}$ associated with a fetal tachycardia of 185 beats per minute. The rest of the exam was unremarkable. An emergency Caesarean section indicated for onset of chorioamnionitis resulted in the removal of a male baby, born asphyxiated; Apgar 7 to M1, 8 and 10 to M5 and M10 and $2440 \mathrm{~g}$. The uterus was partitioned at its upper two-thirds (Figure 6). The operative consequences were simple. Checkups looking for associated malformations are not done because the patient did not have the necessary financial means.

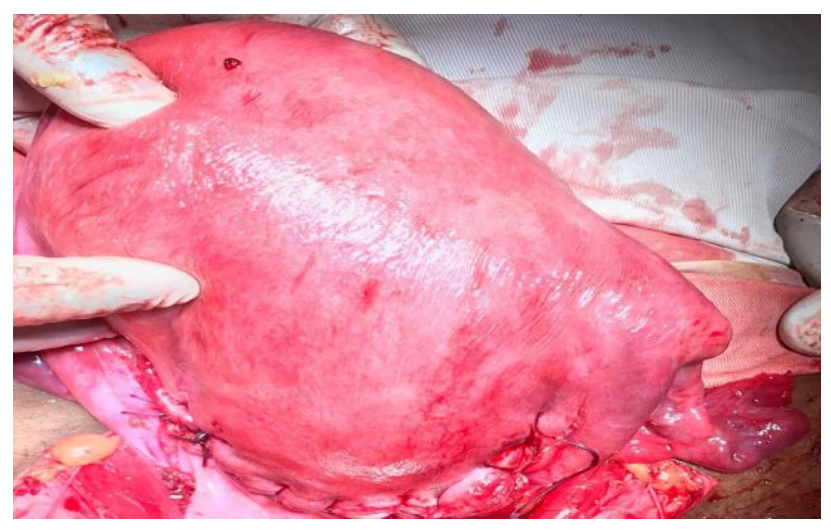

Figure 6: Partitioned uterus.

\section{Case-7}

This is a 25-year-old woman, second procedure, with a history of premature falsehood at 5 weeks with amenorrhea. She was admitted to the emergency room for loss of water from two hours to 36 weeks. Obstetric examination found a uterine height of $30 \mathrm{~cm}$. Speculum 
examination confirmed the loss of meconium color. The vaginal examination showed a centered soft cervix, dilated to $2 \mathrm{~cm}$. A cesarean section indicated in urgency for meconium amniotic fluid with small dilation, made it possible to extract a female baby in cephalic presentation, born asphyxiated, Apgar 8/10 in the first minute and $10 / 10$ in the fifth and the tenth minute, weighing $2500 \mathrm{~g}$. Discovery of a true unicornuate uterus (Figure 7). The operative consequences were simple. Additional examinations looking for associated malformations were not done.

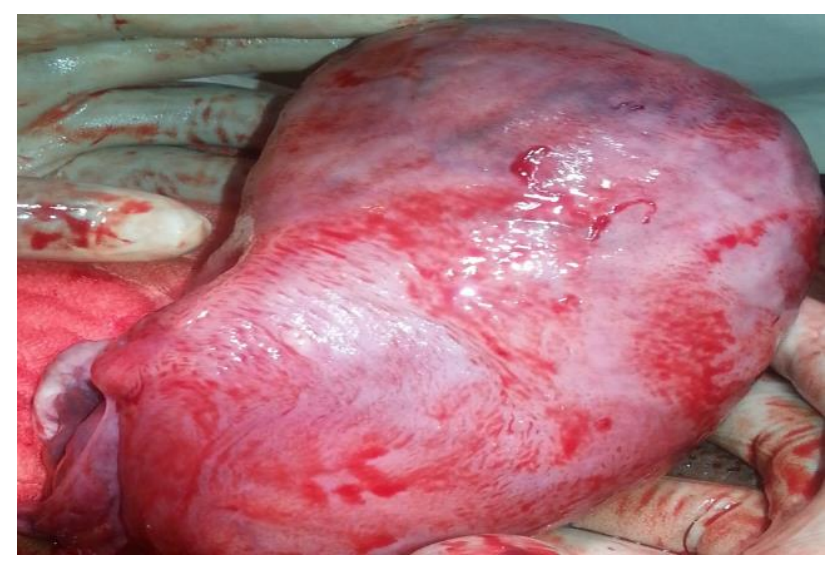

Figure 7: True unicornuate uterus.

\section{Case-8}

This is a 21-year-old primigest patient seen in the obstetric emergency department for an unexplained generalized tonic-clonic convulsive seizure at 39 weeks and 5 days. The pregnancy was spontaneous and progressing normally until then. The patient had no history of high blood pressure or epilepsy. The disease is summed up by the appearance of a generalized tonicclonic convulsive seizure without prodrome followed by loss of urine, emission of drooling and post-critical loss of consciousness of about one minute, which motivates his consultation.

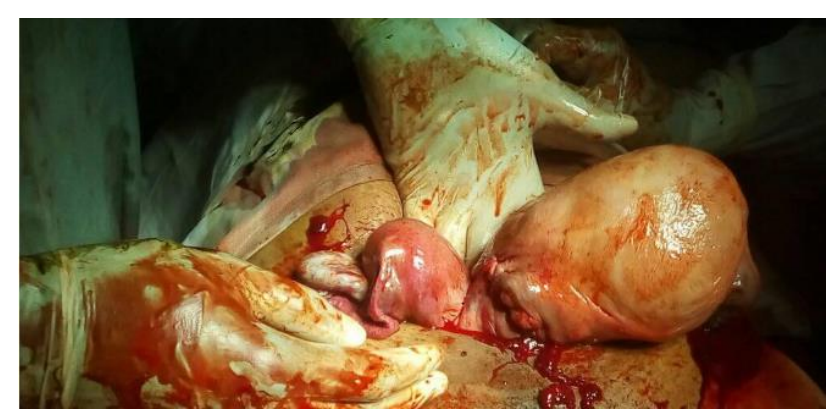

Figure 8: Didelphic uterus.

On entry clinical examination was unremarkable. The fetal heartbeat recording showed fetal bradycardia at 100 beats per minute. An emergency cesarean was performed for fetal bradycardia.
An emergency Caesarean section indicated for fetal bradycardia allowed for difficult extraction in cephalic presentation of a male baby, Apgar at 9/10 at the fifth minute and weighing $2240 \mathrm{~g}$. On exteriorization of the uterus outside the peritoneal cavity, we discovered a didelphic uterus (Figure 8). The pregnancy was developing in the left hemi-uterus. Examination of the vagina at the end of the operation showed a longitudinal median septum with two vaginas and two permeable collars. The postoperative was normal. She was released from the hospital on the fifth day. The seizure did not come back and the neurological examinations performed were normal.

\section{Case-9}

This is a 26-year-old female, primigest, with a history of two threatened preterm delivery at 16 weeks of amenorrhea and 19 weeks of amenorrhea. She was admitted to the emergency room with genital bleeding at 38 weeks of amenorrhea, diagnosed as placenta previa. An emergency Caesarean section for hemorrhagic placenta previa breeched a male baby, apgar 10/10, weighing $2240 \mathrm{~g}$. On exteriorization of the uterus, discovery of a left hemi-uterus measuring 3 times $5 \mathrm{~cm}$ communicating with the left tube. The operative consequences were simple.

\section{Case-10}

This is a 26-year-old primigravida woman, with no specific history, admitted to the emergency room for pelvic pain at 37 weeks of amenorrhea and 2 days. Clinical examination found a uterine height of $32 \mathrm{~cm}$ and vaginal examination revealed a centered soft cervix, dilated to $4 \mathrm{~cm}$. And the fetal heartbeat recording showed severe fetal tachycardia. An emergency caesarean section for severe fetal tachycardia to extract a cephalic baby, female, apgar 10/10 and weighing $2700 \mathrm{~g}$. On exteriorization of the uterus, we found that it was bicornuate. The operative consequences were simple.

\section{Case-11}

This is a 24-year-old woman, fifth gesture, zero living children, 4 voluntary terminations of pregnancy, two by instruments and two by medication. She was admitted to the emergency room with pelvic pain at 14 weeks of amenorrhea. In fact, one week before her admission she had pelvic pain such as uterine contractions calmed by conventional antispasmodics. Then on the day of admission (08/20/18), sudden onset of stabbing pain associated with minimal genital bleeding, dizziness and the notion of loss of consciousness.

The physical examination showed a conscious patient, a blood pressure of $110 / 70 \mathrm{mmhg}$, pale conjunctiva, a heart rate of 98 beats per minute and a respiratory rate of 20 cycles per minute. The abdomen was soft to the palpation. Speculum examination revealed minimal non- 
active bleeding of endo-uterine origin. Vaginal examination showed a closed, posterior, long cervix and a latero-uterine mass on uterine mobilization. The urine dipstick pregnancy test was positive.

A standard pelvic ultrasound, requested urgently, diagnosed a latero-uterine mass of $51 \mathrm{~mm}$ associated with a hemoperitoneum.

Emergency laparotomy indicated for ruptured ectopic pregnancy complicated by clinical anemia. However, when opening the abdomen, a bicornuate uterus was discovered with rupture of the right hemi-uterus (Figure 9). The fetus had died intra-abdominally, the sex of which was difficult to determine. There is also a hemoperitoneum estimated at $600 \mathrm{ml}$. The operative consequences were simple. Check-ups for associated malformations were normal.

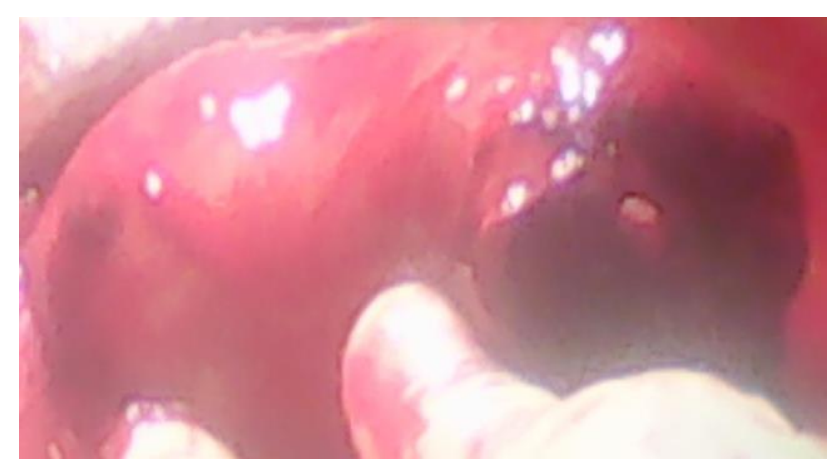

Figure 9: Bicornuate uterus with rupture of the right hemi-uterus.

\section{DISCUSSION}

Most uterine malformations can be explained by a defect or arrest in one of three phases in the development of the following mullerian ducts: migration of muller's ducts to the urogenital sinus (6th - 9th), joining the lower third of the Müllerian ducts forming the uterine cavity and the upper two thirds of the vagina, the resorption of the intermullerian partition (13th-17th century).

Thus, the absence of migration or incomplete caudal migration of the mullerian ducts to the urogenital sinus will be responsible for atresia and/or complete or incomplete uterine aplasia. A defect in the fusion of the Müllerian ducts leads to uterine duplication (didelphus uterus, bicornuate uterus). Failure to merge the resorption ducts of the inter-Müllerian septum leads to a septate uterus. $^{3}$

The prevalence of congenital uterine malformations in the population is estimated at between $4 \%$ to $7 \%$ in $2018 .^{10}$ Although this prevalence remains inaccurate given the asymptomatic nature of these malformations 7 , 8. Imaging techniques such as 3D ultrasound, 3D hysterosonography and MRI have only been available for a few years. ${ }^{8}$ We have identified 3 cases of bicornuate uterus, 3 cases of didelphic uterus, 3 cases of pseudounicorn uterus, one case of septate uterus and one case of true unicornuate uterus.

Several studies show that uterine malformations are most often diagnosed during infertility check-ups and repeated miscarriages. ${ }^{7,8,11}$ In our series, the 9 cases are discovered during the cesarean section and one case during a routine assessment of threatened preterm delivery. This is due to the fact that it is a study carried out in a public hospital center where most patients cannot afford specialized imaging examinations.

Uterine malformations favor an increase in obstructed presentation. Indeed, many authors have described with $25-30 \%$ of breech presentations. ${ }^{11,12}$ and $3-4 \%$ of transverse presentations. ${ }^{11,13}$ This is largely explained by the high rate of caesarean sections performed in malformed uterus compared to uteri without abnormalities. ${ }^{14-16}$ In 2011, Hua et al published on the obstructive outcome of 203 patients with a malformed uterus and showed that premature delivery, foot presentations and the number of cesarean sections had significantly increased. ${ }^{17}$ However, in porcu and heckenroth's series, most deliveries take place vaginally and the indications for Caesarean section were purely obstetric. $^{18}$ In our series, we found two cases of podal presentations and two cases of cross-sectional presentations, and all of them were patient. gave birth by caesarean section. Thus, it is necessary to better define the indications for cesarean section according to the type of obstructed presentation and/or the type of malformation.

The malformed nature of the uterus and the possible limitation of the distension associated with it could raise concerns about an increased risk of uterine rupture. Most studies show that uterine rupture in uterine malformations was almost associated with a scarred uterus. However guinard in his series, found a uterine rupture occurring on a non-cicarticiel pseudocorne uterus. In our series we found a uterine rupture in a non-scarred bicornuate uterus. ${ }^{11}$

The obstetric prognosis is generally altered in the event of malformations. According to Ludmier et all, septate uteri have a poorer obstetric prognosis than bicornuate uteri, while Ma et al and Shuiqing et al believe that the risk is similar for the two subtypes. ${ }^{19-21}$ Zhang et al find that patients with septate uteri have a poor obstetric prognosis compared to unicornuate uteri. For the majority of authors, uteruses with an arched bottom behave in a similar way to non-malformed uteruses 18 . In our series, we observed 3 cases of fetal death, 2 of which occurred in a bicornuate uterus and 1 in a pseudo-horn uterus in which the pregnancy was localized on the rudimentary horn.

It has been shown that pregnancy vascular pathologies and intrauterine growth retardation were significantly 
increased in malformed uterus. ${ }^{22,23}$ Guinard found in his study a rate of intrauterine growth retardation less than or equal to 10th percentile. ${ }^{11}$ In our series, the mean birth weight was g. We observed 4 cases of severe intrauterine growth retardation, ie a birth weight below the 3rd percentile. Furthermore, we did not find any pregnancy vascular pathology.

Check-ups performed for associated renal malformations were normal. However, some patients did not have the financial means to do these kinds of check-ups.

\section{Limitation}

Our work is obviously linked to the fact that it is a serial study of 11 cases. However, a study of several cases remains difficult to carry out because our center does not have $3 \mathrm{D}$ imaging devices and patients who consult for infertility problems are rare. The diagnosis of a uterine malformation can be suggested on pelvic ultrasound and hysterosalpingography, but only laparoscopy can definitively confirm the diagnosis and correctly classify the malformation by studying the external contours of the uterus. In our series, the diagnosis of the malformation was almost made during cesarean section or during laparotomy for a picture of ectopic pregnancy (Figure 10).

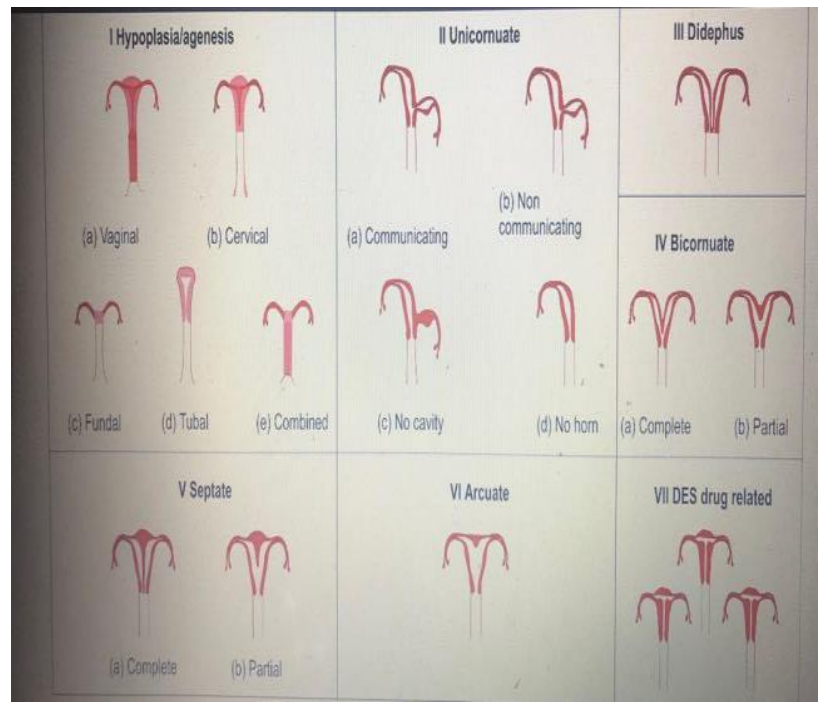

Figure 10: Classification of congenital uterine anomalies according to the American fertility society.

Table 1: Summary of cases.

\begin{tabular}{|c|c|c|c|c|c|c|c|}
\hline & Age & SA* & Gesture & Presentation & Malformation & $\mathbf{P N} * *$ & From the baby \\
\hline 1st case & 22 & 37 & 1 & Céphalique & Didelphic uterus & 1680 & Living \\
\hline 2nd case & 29 & 41 & 3 & Transversale & Bicornuate uterus & 2500 & Living \\
\hline 3rd case & 24 & 17 & 2 & - & Pseudo-horn uterus & 200 & Living \\
\hline 4th case & 22 & 38 & 2 & Transversale & Didelphic uterus & 1850 & Living \\
\hline 5th case & 35 & 42 & 4 & Céphalique & Pseudo-horn uterus & 3500 & Living \\
\hline 6th case & 26 & 37 & 1 & Siège & Septate uterus & 2440 & Living \\
\hline 7th case & 25 & 36 & 2 & Céphalique & True unicorn uterus & 2500 & Living \\
\hline 8th case & 21 & 39 & 1 & Siège & Didelphic uterus & 2240 & Living \\
\hline 9th case & 26 & 38 & 1 & Céphalique & Pseudo-horn uterus & 2240 & Living \\
\hline 10th case & 26 & 37 & 1 & Céphalique & Bicornuate uterus & 2700 & Living \\
\hline 11th case & 24 & 17 & 5 & - & Bicornuate uterus & & Deceased \\
\hline Moyen & 23,63 & 34,45 & 1,8 & - & & 2215 & \\
\hline
\end{tabular}

\section{CONCLUSION}

Congenital uterine malformations are relatively common and often asymptomatic. Their exact impact remains difficult to assess. They can have an impact on reproduction. The presence of certain types of congenital uterine abnormalities can adversely affect the outcome of a possible pregnancy. Screening is based on an early and precise diagnosis. In Madagascar, only modernization of imaging techniques and early monitoring would make it possible to provide better care for pregnant women with congenital uterine malformations. It should be remembered that when diagnosing a malformation, urinary tract imaging should be performed due to the frequent associated abnormalities.
Funding: No funding sources Conflict of interest: None declared

Ethical approval: Not required

\section{REFERENCES}

1. Doruk A, Gozukara I, Burkaş G, Bilik E, Dilek TU. Spontaneous twin pregnancy in uterus bicornis unicollis. Cas Repor Obstet Gynecol. 2013;2013.

2. Pentti K, Heinonen. Twin pregnancy in the congenital malformed uterus. J Organizat Behav. 2016.

3. Ali O, Hakimi I, Chanana A, Habib MA, Guelzim K, Kouach J, Rahali DM. Grossesse sur utérus 
cloisonné menée à terme: à propos d'un cas avec revue de la literature. Pa Afric Medic J. 2015;22(1).

4. Ngichabe S, Sura M. Placenta Percreta in a gravid bicornuate unicollis uterus. Cas Repor Obstet Gynecol. 2017;2017.

5. Fuchs F, Guillot E, Cordier AG, Chis C, Raynal P, Panel P. Rupture of non-communicating rudimentary pregnant uterine horn in a pseudo-unicornuate uterus at 23 weeks of amenorrhea. Case rep Gynecol, Obstet F. 2008;36(4):400.

6. Vale-Fernandes E, Teixeira N, Cadilhe A, Rocha MJ. Uterine Rupture at 18 Weeks of Pregnancy in the Context of Malformed Uterus. Act Medic Portugue. 2016;29(10):667-70.

7. Itchimouh $\mathrm{S}$, Khabtou K, Mahdaoui S, Boufettal H, Samouh N. Uterine rupture in a patient with bicornuate uterus at 12 weeks of amenorrhea: about a case. Pa Afric Medic J. 2016;24:153

8. Ali O, Hakimi I, Chanana A, Habib MA, Guelzim K, Kouach J, et al. Grossesse sur utérus cloisonné menée à terme: à propos d'un cas avec revue de la literature. Pa Afric Medic J. 2015;22(1).

9. Ejnes L, Desprez B, Bongain A, Gillet JY. Twin pregnancy in a unicornuate uterus with a rudimentary horn. Gynecol, Obstet \& Fert. 2003;31(7-8):627-8.

10. LaHood J, You W. Uterine torsion and subsequent rupture in a gravid bicornuate uterus associated with an elevated alpha-fetoprotein. Cas Repor. 2018;2018.

11. Guinard E, Subtil D, Deruelle P. Congenital Müllerian anomalies and delivery: analysis of 304 cases between 2000 and 2010 at the University Hospital of Lille. Gynecol, Obstet Fert. 2014;42(78):471.

12. Raga F, Bauset C, Remohi J, Bonilla-Musoles F, Simón C, Pellicer A. Reproductive impact of congenital Müllerian anomalies. Hum Reproduct. 1997;12(10):2277-81.

13. Erez O, Dukler D, Novack L, Rozen A, Zolotnik L, Bashiri A, et al. Trial of labor and vaginal birth after cesarean section in patients with uterine Müllerian anomalies: a population-based study. Americ J Obstet Gynecol. 2007;196(6):537-e1.

14. Acién P. Reproductive performance of women with uterine malformations. Hum Reproduct. 1993;8(1):122-6.
15. Heinonen PK, Saarikoski S, Pystynen P. Reproductive perfomance of women with uterine anomalies. Anevaluation of 182 cases. Acta Obstet Gynecol Scand 1982;62(2):157-62.

16. Sloan SW. Obstruction of labour due to incarceration of non gravid corpus in a case of uterus didelphys. Int J Obstet Gynaecol.1958.65(1):110-1.

17. Hua M, Odibo AO, Longman RE, Macones GA, Roehl KA, Cahill AG. Congenital uterine anomalies and adverse pregnancy outcomes. Americ J Obstet Gynecol. 20111;205(6):558-e1.

18. Porcu G, Heckenroth H. Uterine abnormalities and infertility. EMC Gynecol Obstet. 2005;2:185-97.

19. Ludmir J, Samuel P, Brooks S, Mennuti MT. Pregnancy outcome of patients with uncorrected uterine anomalies managed in high-risk obstetric setting. Obstet Gynecol. 1990;75:906-10.

20. Ma S, Bian X, Lang J. Pregnancy and its outcome in women with malformed uterus. Zhonghua Yi Xue Za Zhi. 2008;8(7):415-7.

21. Shuiqing M, Xuming B, Jinghe L. Pregnancy and its outcome in women with malformed uterus. Chin Med Sci J. 2002;17:242-5.

22. Jagusiak A, Gondry Ml, Sergent Ml, Cabry Ml. Interet de l'elastographie cervicale chez les patientes en menace d'accouchement premature: une etude prospective.

23. Ben Rafael Z, Seidman DS, Recabi K, Bider D, Mashiach S. Uterine anomalies. A retrospective matched-control study. J Reprod Med. 1991;36(10):723-7.

24. Am Fertil So. The American Fertility Society classification of adnexal adhesions, distal tubal occlusion secondary to tubal ligation, tubal pregnancies, Mullerian anomalies and intrauterine adhesions. Fertil Steril. 1988;49:944-55.

Cite this article as: Housni I, Tanjona RA, Rakotonirina MA, Romuald R, Fleurian S, Halissoit BA. Uterine malformations and pregnancy: about 11 cases seen university hospital center of gynecologyobstetric Befelatanana Antananarivo Madagascar. Int J Reprod Contracept Obstet Gynecol 2020;9:4670-6. 